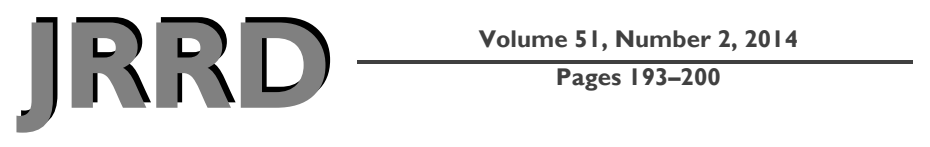

\title{
Influence of physical capacities of males with transtibial amputation on gait adjustments on sloped surfaces
}

\author{
Karine Langlois, MSc; ${ }^{1}$ Coralie Villa, MSc $;{ }^{1}$ Xavier Bonnet, PhD $;{ }^{2}$ François Lavaste, $\mathrm{PhD} ;{ }^{1,3}$ Pascale Fodé, MD, \\ MSc; ${ }^{3}$ Noel Martinet, $\mathbf{M D} ;{ }^{4}$ Hélène Pillet, $\mathbf{P h D}^{{ }^{*}}$ \\ ${ }_{1}^{1}$ Arts et Metiers ParisTech, Paris, France; ${ }^{2}$ PROTEOR, Handicap Technologie, France; ${ }^{3}$ INI, Centre d'Etude et de \\ Recherche sur l'Appareillage des Handicapés, Woippy Cédex, France; ${ }^{4}$ Centre de médecine physique et de réadaptation \\ Louis Pierquin, Nancy Cedex, France
}

\begin{abstract}
The aim of the study was to investigate how kinematic and kinetic adjustments between level and slope locomotion of persons with transtibial amputation are related to their individual muscular and functional capacities. A quantified gait analysis was conducted on flat and slope surfaces for seven patients with transtibial amputation and a control group of eight subjects to obtain biomechanical parameters. In addition, maximal isometric muscular strength (knee and hip extensors) and functional scores were measured. The results of this study showed that most of the persons with transtibial amputation could adapt to ramp ascent either by increasing ankle, knee, and hip flexion angles of the residual limb and/or by recruiting their hip extensors to guarantee enough hip extension power during early stance. Besides, 6-minute walk test score was shown to be a good predictor of adaptation capacities to slope ascent. In ramp descent, the increase of knee flexion moment was correlated with knee extensor strength and residual-limb length. However, no correlation was observed with functional parameters. Results show that the walking strategy adopted by persons with transtibial amputation to negotiate ramp locomotion mainly depends on their muscular capacities. Therefore, muscular strengthening should be a priority during rehabilitation.
\end{abstract}

Key words: biomechanics, gait analysis, joint power, kinematics, kinetics, muscle strength, rehabilitation, slope walking, stump length, transtibial amputation.

\section{INTRODUCTION}

The activity level of persons with transtibial amputation depends upon their physical condition, their prosthetic components, and how they use their prosthesis. Different kinds of evaluations are currently used to assess locomotion outcomes of the patients. For example, muscular capacities of the patients are evaluated by quantifying maximal isometric muscular strengths [1]. Functional evaluations are also used to give global scores based on self-reported questionnaires such as the Prosthetic Profile Amputee-Locomotor Capacities Index (PPA-LCI) and the 36-Item Short Form Health Survey (SF-36) or on performance measures such as the 6-minute walk test (6MWT) [2]. Finally, quantitative analysis of gait provides detailed biomechanical parameters useful to the understanding of gait limitations [3]. Most often, these parameters (muscular, functional, and biomechanical) are studied independently. Only a few studies have attempted to correlate these parameters during both level surface and stair locomotion [4-5].

\footnotetext{
Abbreviations: $6 \mathrm{MWT}=6$-minute walk test, PPA-LCI = Prosthetic Profile Amputee-Locomotor Capacities Index, SF36 = 36-Item Short Form Health Survey.

*Address all correspondence to Hélène Pillet, PhD; Arts et Metiers ParisTech, Laboratoire de BioMécanique, 151 bd de l'hôpital 75013 Paris, France; +0033144246469; fax: +0033144246366. Email: helene.pillet@ensam.eu

http://dx.doi.org/10.1682/JRRD.2013.05.0118
} 
In the literature, the modifications of biomechanical parameters that occur when walking on slopes compared with level walking have already been well described for asymptomatic subjects. In brief, during ramp ascent, the major adjustments are the increase of ranges of motion of lower-limb joints and of hip external flexion moment [67]. These alterations were associated with a higher generated ankle power at the end of the stance phase and a higher generated hip power at the beginning of the stance phase [8]. During ramp descent, an increase of knee flexion angle, knee external flexion moment, and absorbed knee power have been reported [6-8].

Literature about persons with transtibial amputation during level walking shows that the peaks of power at the lower-limb joints of persons with transtibial amputation are different from those of asymptomatic subjects because of the loss of ankle muscles. Sadeghi et al. showed a decrease in absorbed knee power together with an increase in generated hip power [9] in the residual limb in order to compensate for the absence of active ankle plantar flexion of prosthetic feet. These impairments are expected to worsen when walking uphill with the need to lift the body $[6,10]$. To date, three studies have analyzed the locomotion of persons with transtibial amputation in slopes. Vrieling et al. analyzed kinematical alterations between level walking and slope ascent and descent [11]. During uphill walking, they observed an increase in hip and knee flexions at heel strike on the prosthetic side. During downhill walking, the main alteration was the increase in residual knee flexion in late stance. However, in their study, the inclination of the slope was limited to 5 percent and dynamic parameters were not estimated. On the contrary, Vickers et al. [12] and Fradet et al. [13] calculated both kinematic and kinetic parameters for persons with transtibial amputation compared with asymptomatic subjects. Vickers et al. showed that persons with transtibial amputation reduced their speed and hip and knee flexion ranges of motion and generated less moment in the knee, particularly during descent [12]. In these two studies, the inclinations of the slopes were 9 percent and 13 percent, but these authors did not perform any comparison with level walking as a reference.

Previous studies aimed at establishing relationships between muscular parameters and gait characteristics have already shown some significant correlations. However, all studies have been performed on flat surfaces to date $[2,5,14]$.

To our knowledge, no studies have investigated the link between muscular forces, functional scores, and bio- mechanical parameters during transtibial amputation gait on slopes. Considering the adjustments already observed for asymptomatic subjects during ramp ambulation, it can be hypothesized that the muscular capacities of persons with transtibial amputation, in particular at the hip in ascent and at the knee in descent, will have a high effect on their ability to biomechanically adapt their gait on slopes. It is also to be expected that this ability will be related to functional scores traditionally used to evaluate the activity level of persons with lower-limb amputation.

In this framework, the aim of this study was to investigate how kinematic and kinetic adjustments between level and slope locomotion of persons with transtibial amputation are related to their individual muscular and functional capacities.

\section{MATERIALS AND METHODS}

\section{Subjects}

Seven active male patients with transtibial amputation (mean age $48 \pm 13$ yr, height $1.74 \pm 0.05 \mathrm{~m}$, mass $83 \pm 10 \mathrm{~kg}$ ) participated in the study. All patients were amputated for traumatic reasons, except one for tumoral cause, and were wearing their own prosthetic foot. Eight asymptomatic subjects (mean age $46 \pm 19 \mathrm{yr}$, height $1.77 \pm$ $0.10 \mathrm{~m}$, mass $68 \pm 13 \mathrm{~kg}$ ) were recruited to obtain reference data of the biomechanical parameters.

\section{Protocol}

Data collection was conducted in two different motion analysis laboratories with the same instrumentation, protocol, and operators.

Regarding the biomechanical analysis, patients and control subjects were equipped with 54 markers whose positions were recorded with an optoelectronic motion analysis system (Vicon V8i; Oxford, United Kingdom) in accordance with the protocol described by Pillet et al. [15]. The inertial parameters of the body used in inverse dynamics to compute kinetic parameters were obtained according to the method proposed by Pillet et al. [15] Subjects were asked to walk at a comfortable self-selected speed on a flat pathway and on a 12 percent inclined slope. Two force platforms (100 Hz, AMTI; Watertown, Massachusetts) were used to measure ground reaction forces. Five successful trials (when each lower limb hit one force platform) were recorded for each condition. 
Regarding the muscular and functional evaluations, only patients with amputation were tested during a clinical examination conducted prior to gait analysis. The isometric strength of hip extensors, hip abductors, and knee extensors was assessed using a handheld dynamometer according to the protocol described by Maffiuletti [1]. The average force over three measurements of isometric maximal voluntary contraction was scaled by the lever arm (taken from the dynamometer to the joint axis) and the patient's weight for each group of muscles.

The residual-limb length was measured from the lateral epicondyle of the knee to its bone limb and normalized according to the sound-limb length measured from the lateral epicondyle of the knee to the lateral malleolus.

In addition, all subjects with amputation completed PPA-LCI and SF-36 self-reported questionnaires [1617]. A functional score out of 70 was calculated from the PPA-LCI, and a score out of 30 was calculated from the mobility item of the SF-36. The functional capacities of subjects with amputation were tested with the 6MWT, measuring the distance covered in 6 min by the patients on level surface [2].

\section{Data Analysis}

Spatiotemporal parameters, anatomical frames, and segmental and articular kinematics and kinetics of the lower limbs were computed according to Pillet et al. [15]. All parameters were estimated for level walking and for the ascent and the descent of the slope.

Several biomechanical parameters identified as being significantly modified for asymptomatic subjects when walking on slopes were selected based on previous literature $[6,8]$. Thus, for each situation (level, uphill, and downhill walking) the following spatiotemporal parameters were computed: gait speed; step length; percentage of stance phase; and the amplitude of flexion angles of the ankle, knee, and hip joints. Then, the following parameters were quantified during level and uphill walking: the ankle flexion angle at the end of the weight-acceptance phase (20\% of the gait cycle), the knee flexion and hip flexion angles at heel strike, the peak generated hip power in early stance, and the peak generated ankle power in late stance. Likewise, the following parameters were quantified during level and downhill walking: the knee flexion angle at the end of the single-stance phase ( $40 \%$ of gait cycle), the hip flexion angle at heel strike, the peak knee moment in early stance, and the peak knee power in early stance. All these parameters were evaluated on the residual-limb side for subjects with amputation and as the mean of right and left sides for control subjects. Variations of biomechanical parameters between level and slope walking were expressed by computing the difference of the value of each biomechanical parameter during ramp ascent/descent minus its value during level walking (Figure). These variations were considered as quantitative parameters characterizing the adjustment strategy.

\section{Statistics}

A Lilliefors test was used to test normality on all parameters. A correlation analysis was performed between muscular strengths, functional scores, and all quantitative biomechanical parameters defined to characterize the adjustment strategy. Pearson correlation coefficients were calculated in case of normality and Spearman correlation coefficients in case of nonnormality. The level of significance was set at $\alpha=0.05$.

\section{RESULTS}

\section{Muscular Parameters and Functional Scores}

The PPA-LCI score (considered as the reference test for the locomotion of persons with amputation) results were between 62 and 70 out of a maximal score of 70 (with 5 patients who scored 70). This finding suggests that for our population, the PPA-LCI was not discriminatory enough; this limit has been previously observed by Miller et al. [17]. The scores for SF-36 and 6MWT are reported in Table 1.

Concerning muscular parameters, the strengths of gluteus maximus and quadriceps of residual and intact limbs are summarized in Table 1. For all patients, there was no deficiency of gluteus maximus, whereas a decrease of the muscular strength of the quadriceps was observed. Pearson correlation showed that quadriceps strength was correlated with stump length $(r=0.95, p=0.001)$.

\section{Correlations Among Biomechanical Parameters Variations and Muscular and Functional Outcomes}

\section{Ramp Ascent}

Table 2 presents the variation in the biomechanical parameters of the residual limb between slope ascent and level walking.

Subjects with transtibial amputation walked at an average speed of $1.32 \pm 0.08 \mathrm{~m} / \mathrm{s}$ on the flat surface. For the 
(a)
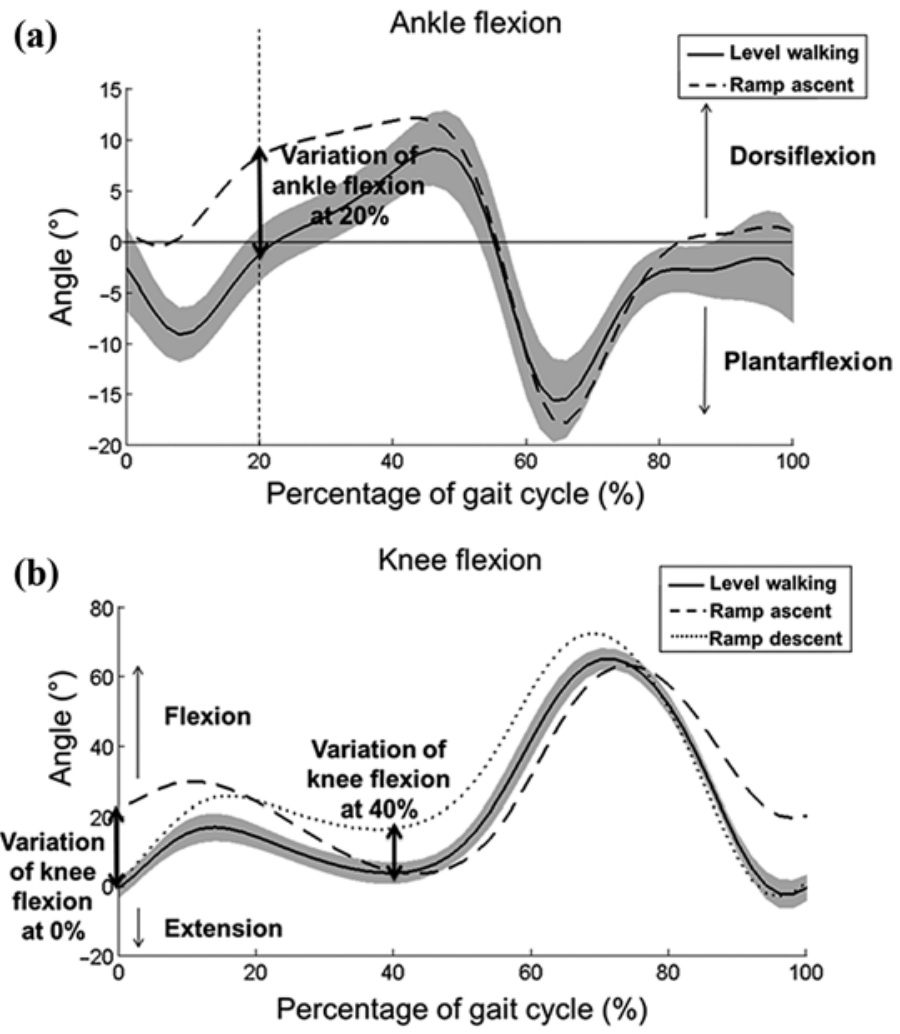

(c)

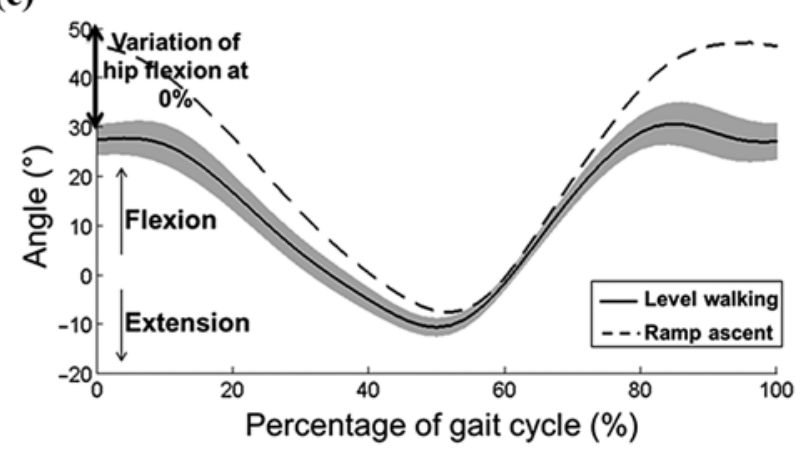

(d)

Knee moment

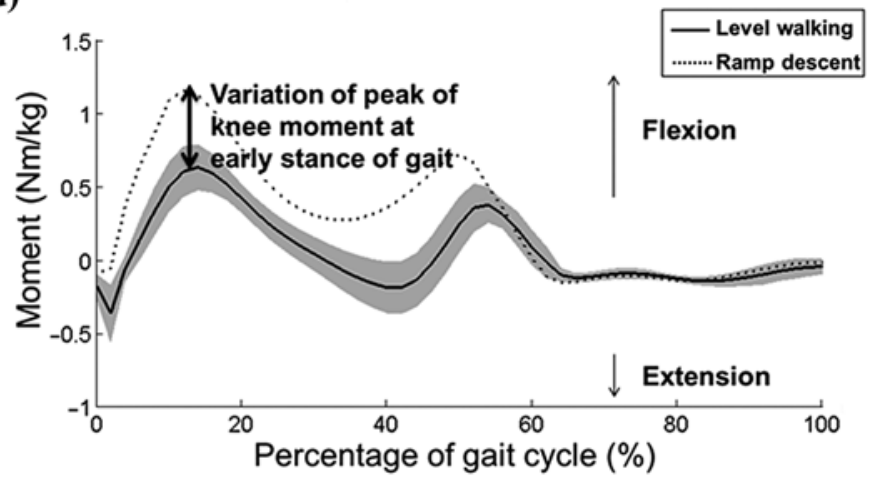

(e)

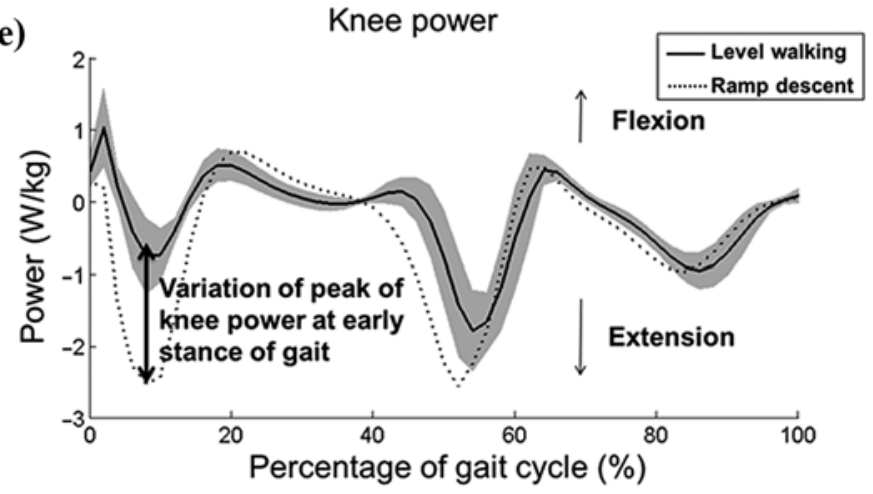

(f)

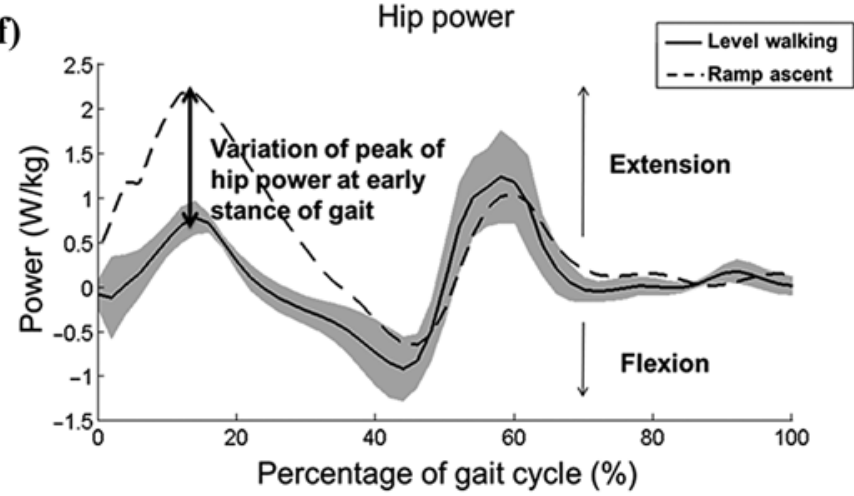

Figure.

Patterns of kinematic and kinetic parameters (average of control group) during ramp (a)-(c),(f) ascent and (b),(d)-(e) descent. Biomechanical parameters of interest were extracted and represented on each graph.

control group, the walking velocity was $1.36 \pm 0.12 \mathrm{~m} / \mathrm{s}$. During ramp ascent, the average speed was $1.14 \pm 0.25 \mathrm{~m} / \mathrm{s}$ for the transtibial amputation group against $1.24 \mathrm{~m} / \mathrm{s}$ for the control group. The decrease in gait speed was correlated with the muscular strength of hip extensors (gluteus maximus) $(r=0.78, p=0.04)$.

An increase in the peak hip power during early stance was observed in the population with transtibial amputa- tion. The increase in the peak hip power was correlated with the muscular strength of hip extensors (gluteus maximus) ( $r=0.82, p=0.03)$, with the SF-36 score $(r=0.88$, $p=0.01)$, and with the 6MWT score $(r=0.83, p=0.02)$.

Concerning kinematic parameters, hip and knee flexion angles increased at initial contact and ankle dorsiflexion angle increased at 20 percent of gait cycle. Moreover, these increases were correlated for knee and hip $(r=-0.94$, 
Table 1.

Functional scores and muscular strengths of gluteus maximus and quadriceps for both limbs and residual-limb length.

\begin{tabular}{|c|c|c|c|c|c|c|c|}
\hline \multirow{2}{*}{ Patient } & \multirow{2}{*}{$\begin{array}{c}\text { Residual Limb } \\
\text { Length (\% of intact } \\
\text { limb length) }\end{array}$} & \multicolumn{2}{|c|}{$\begin{array}{c}\text { Gluteus maximus } \\
(\mathrm{Nm} / \mathrm{kg})\end{array}$} & \multicolumn{2}{|c|}{$\begin{array}{l}\text { Quadriceps } \\
\text { (Nm/kg) }\end{array}$} & \multirow{2}{*}{$\begin{array}{c}\text { SF-36 } \\
\text { (maximal } \\
\text { score: } 30)\end{array}$} & \multirow{2}{*}{$\begin{array}{c}\text { 6MWT } \\
\text { (m) }\end{array}$} \\
\hline & & $\begin{array}{c}\text { Residual } \\
\text { Limb }\end{array}$ & $\begin{array}{l}\text { Intact } \\
\text { Limb }\end{array}$ & $\begin{array}{c}\text { Residual } \\
\text { Limb }\end{array}$ & $\begin{array}{l}\text { Intact } \\
\text { Limb }\end{array}$ & & \\
\hline 1 & 27 & 1.1 & 1.2 & 0.2 & 1.1 & 26 & 390 \\
\hline 2 & 63 & 1.5 & 1.6 & 1.2 & 1.9 & 27 & 530 \\
\hline 3 & 83 & 1.7 & 1.6 & 1.2 & 1.5 & 25 & 480 \\
\hline 4 & 62 & 1.2 & 1.1 & 1.4 & 1.6 & 30 & 465 \\
\hline 5 & 27 & 1.1 & 1.2 & 0.3 & 1.2 & 27 & 475 \\
\hline 6 & 35 & 0.6 & 0.7 & 0.5 & 1.0 & 22 & 380 \\
\hline 7 & 32 & 0.7 & 0.7 & 0.3 & 1.2 & 22 & 430 \\
\hline
\end{tabular}

Table 2.

Variation of biomechanical parameters between slope ascent and level walking.

\begin{tabular}{|c|c|c|c|c|c|c|c|c|c|c|}
\hline Subject & $\begin{array}{c}\text { Walking } \\
\text { Velocity } \\
(\mathrm{m} / \mathbf{s})\end{array}$ & $\begin{array}{l}\text { Step } \\
\text { Length } \\
\text { (m) }\end{array}$ & $\begin{array}{c}\text { ROM of } \\
\text { Prosthetic } \\
\left.\text { Ankle ( }{ }^{\circ}\right)\end{array}$ & $\begin{array}{l}\text { ROM of } \\
\text { Residual } \\
\text { Knee }\left(^{\circ}\right)\end{array}$ & $\begin{array}{c}\text { ROM of } \\
\text { Residual } \\
\text { Hip }\left(^{\circ}\right)\end{array}$ & $\begin{array}{c}\text { Knee } \\
\text { Flexion } \\
\text { at Initial } \\
\text { Contact }\left(^{\circ}\right)\end{array}$ & $\begin{array}{c}\text { Hip } \\
\text { Flexion } \\
\text { at Initial } \\
\text { Contact }\left(^{\circ}\right)\end{array}$ & $\begin{array}{c}\text { Ankle } \\
\text { Dorsiflexion } \\
\text { at } 20 \% \text { of } \\
\text { Gait Cycle } \\
\left({ }^{\circ}\right)\end{array}$ & $\begin{array}{c}\text { Peak of } \\
\text { Hip Power } \\
\text { in Early } \\
\text { Stance Phase } \\
\text { (W/kg) }\end{array}$ & $\begin{array}{c}\text { Peak of Ankle } \\
\text { Power Late } \\
\text { Stance Phase } \\
(W / k g)\end{array}$ \\
\hline \multicolumn{11}{|l|}{ Patients } \\
\hline 1 & -0.14 & -0.02 & 0 & 1 & 9 & 6 & -13 & -1 & 0.82 & 0.20 \\
\hline 2 & 0.00 & 0.04 & -10 & -7 & 16 & 27 & -25 & -13 & 1.85 & 0.46 \\
\hline 5 & -0.03 & 0.07 & -2 & -12 & 10 & 11 & -17 & -9 & 1.35 & 0.32 \\
\hline 6 & -0.54 & -0.09 & -4 & -15 & -2 & 6 & -8 & 2 & 0.12 & -0.50 \\
\hline 7 & -0.36 & -0.04 & -2 & -8 & 15 & 3 & -9 & -3 & 0.44 & -0.63 \\
\hline Mean \pm SD & $-0.18 \pm 0.20$ & $-0.01 \pm 0.06$ & $-3 \pm 3$ & $-6 \pm 6$ & $9 \pm 6$ & $11 \pm 8$ & $-14 \pm 6$ & $-4 \pm 5$ & $1.18 \pm 0.73$ & $0.15 \pm 0.53$ \\
\hline $\begin{array}{l}\text { Controls } \\
(\text { Mean } \pm \text { SD) }\end{array}$ & $-0.21 \pm 0.37$ & $0.01 \pm 0.05$ & $4 \pm 2$ & $-7 \pm 4$ & $13 \pm 6$ & $22 \pm 5$ & $-20 \pm 4$ & $-9 \pm 3$ & $1.12 \pm 0.87$ & $0.80 \pm 0.95$ \\
\hline
\end{tabular}

$p=0.002)$ and for ankle and hip ( $r=0.92, p=0.003)$. Kinematic variations were correlated with the 6MWT score $(r=-0.81, p=0.03$ for the ankle; $r=0.81, p=0.03$ for the knee; and $r=-0.84, p=0.02$ for the hip).

\section{Ramp Descent}

Table 3 presents the variation in the biomechanical parameters between slope descent and level walking.

As concerns the residual knee, we found an increase in the flexion angle at mid-stance, in the peak flexion moment, and in the absorbed power in early stance.

The increase in the first peak knee flexion moment in early stance was strongly correlated with muscular strength of the quadriceps ( $r=0.80, p=0.03$ ) and to the residuallimb length $(r=0.89, p=0.01)$. It was also correlated with the variation of the first peak knee power in early stance $(r=-0.90, p=0.01)$.

No correlation was found between the variation of biomechanical parameters and the functional scores or the variation of spatiotemporal parameters.

\section{DISCUSSION}

The present study aimed at identifying the relationships between muscular and functional abilities of persons with transtibial amputation with the biomechanical adaptations when walking on inclined surfaces compared to level surfaces. 
JRRD, Volume 51, Number 2, 2014

Table 3.

Variation of biomechanical parameters between slope descent and level walking.

\begin{tabular}{|c|c|c|c|c|c|c|c|c|}
\hline Subject & $\begin{array}{l}\text { Walking Velocity } \\
(\mathbf{m} / \mathbf{s})\end{array}$ & $\begin{array}{l}\text { Step Length } \\
\text { (m) }\end{array}$ & $\begin{array}{c}\text { ROM of } \\
\text { Prosthetic } \\
\left.\text { Ankle ( }{ }^{\circ}\right)\end{array}$ & $\begin{array}{l}\text { ROM of } \\
\text { Residual } \\
\text { Knee }\left(^{\circ}\right)\end{array}$ & $\begin{array}{c}\text { ROM of } \\
\text { Residual } \\
\text { Hip }\left(^{\circ}\right)\end{array}$ & $\begin{array}{c}\text { Knee Flexion } \\
\text { at Midstance } \\
\left({ }^{\circ}\right)\end{array}$ & $\begin{array}{c}\text { Peak of Knee } \\
\text { Moment in Early } \\
\text { Stance }(\mathrm{Nm} / \mathrm{kg})\end{array}$ & $\begin{array}{c}\text { Peak of Knee } \\
\text { Power in Early } \\
\text { Stance }(W / k g)\end{array}$ \\
\hline \multicolumn{9}{|l|}{$\overline{\text { Patients }}$} \\
\hline 2 & -0.12 & -0.07 & 0 & 4 & -16 & 25 & 0.27 & -0.10 \\
\hline 3 & -0.11 & -0.08 & 0 & 7 & -10 & 16 & 0.64 & -1.05 \\
\hline 4 & -0.13 & -0.09 & -1 & 4 & -15 & 19 & 0.48 & -1.46 \\
\hline 7 & -0.46 & -0.15 & -2 & -3 & -12 & 6 & 0.12 & -0.03 \\
\hline Mean \pm SD & $-0.22 \pm 0.21$ & $-0.11 \pm 0.05$ & $-1 \pm 2$ & $2 \pm 6$ & $-14 \pm 8$ & $14 \pm 7$ & $0.28 \pm 0.21$ & $-0.38 \pm 0.61$ \\
\hline $\begin{array}{l}\text { Controls } \\
\text { (Mean } \pm \text { SD) }\end{array}$ & $-0.11 \pm 0.18$ & $-0.04 \pm 0.05$ & $-1 \pm 5$ & $7 \pm 4$ & $-9 \pm 3$ & $13 \pm 4$ & $0.64 \pm 0.22$ & $-2.24 \pm 0.96$ \\
\hline
\end{tabular}

\section{Ramp Ascent}

The situation of ramp ascent requires a high hip power in early stance to lift the body [8]. In the present study, an increase in the peak hip power in early stance was observed among subjects with amputation. The value of the peak of hip extensors power was highly correlated with the maximal isometric strength of the residual hip extensor (gluteus maximus). Thus, when available, the strength of the hip extensor was used to increase the power supplied to the body. In addition, the decrease of walking velocity observed during ramp ascent compared with level walking [12] was reduced for the patients exhibiting higher hip extensor strength in their residual limb. This velocity variation could be proposed as an individual parameter characterizing the ability of the patient to climb the slope. Finally, the hip extensor strengthening already recommended to compensate for the loss of ankle muscles during level walking [9,18-19] would be all the more beneficial during slope ascent.

Regarding kinematic parameters variations, the prosthetic ankle was more dorsiflexed at the end of the bearing period, and the flexions of the residual knee and hip were greater at heel strike. However, these increases were of different magnitudes among patients with amputation. As already described in the literature, the increases of these kinematic parameters were higher for the control group than for the transtibial patients of this study [12]. Considering the adaptations of asymptomatic subjects as a reference, it is assumed that the capacity to increase lower-limb mobility would be directly related to the ability to adapt to slope ascent.
The results also showed that a lack of mobility at the ankle would affect kinematics of the overlying joints as knee and hip parameters were correlated with ankle dorsiflexion parameter. Using the Proprio Foot prosthesis set in ramp mode, Fradet et al. have previously observed that having a larger angle of ankle flexion during ramp ascent improved knee kinematics [13].

The results of this study showed that most of the subjects with transtibial amputation could adapt to ramp ascent either by altering ankle, knee, and hip flexion angles of the residual limb and/or by recruiting their hip extensors to guarantee enough hip extension power during early stance to walk uphill.

The increase of kinematic parameters and the increase of hip power in early stance were correlated with the 6MWT scores. Although the 6MWT is not specific to this situation, a good performance in this endurance test was a predictor of an adaptation close to the one of asymptomatic people from a kinematic point of view.

\section{Ramp Descent}

The adaptations to ramp descent were observed to be mainly realized by the knee for asymptomatic subjects $[6,8]$. In fact, the knee flexion during stance phase enables subjects to lower their center of gravity. However, this increase of flexion induces an increase in the peak flexion moment that must be controlled by the quadriceps [6]. It must be noted that the maximum isometric quadriceps strength of the residual side was less than half of the intact side in seven transtibial patients, thus jeopardizing the control of the knee. The increase in the peak knee flexion moment in early stance found for our group of subjects varied between patients and was 
correlated with the quadriceps strength of the residual knee. It could be assumed that patients with low quadriceps force limit their knee flexion moment in descent.

Our results also showed that maximal quadriceps strength was highly correlated with stump length. Indeed, Fraisse et al. previously demonstrated that muscular strength loss was more important in the case of short residual limbs [20]. Contrary to the findings for ramp ascent, no correlation between the previously mentioned parameter, functional score, and variation of spatiotemporal parameters was found during ramp descent.

Finally, qualitative observation of strategies for walking downhill showed important variations among subjects: some were able to control their descent increasing knee peak moment like the control group, some reduced gait speed and step length, and others swept along the ramp. This is consistent with the findings of Hunter et al., who suggested that walking downhill resulted from a compromise between the necessity of ensuring stability and the concern for minimizing energy, which can be more difficult to achieve for people with gait disorders [21].

\section{Study Limitations}

Few subjects were recruited in the study and they wore different prosthetic components. This heterogeneity, although inherent to this type of study, could affect the patterns of gait of the patients, although only to a certain extent because all prosthetic feet were energy storing types [22]. This study is the first to investigate the relationship between functional and muscular capacities and adaptation to ramp ambulation in persons with transtibial amputation. The heavy experimental procedure proposed in this explorative study should now be simplified to complete the results through an extensive study on the selected parameters.

\section{CONCLUSIONS}

The present study linked muscular capacities of the residual limb with biomechanical walking adjustments between level and inclined surfaces for patients with transtibial amputation. Results suggested that muscular strengthening of hip and knee extensors during rehabilitation could enhance ability to negotiate ramps. This is all the more true for patients with short residual limbs who usually present reduction of the quadriceps strength in the residual limb.
Concerning functional evaluations of patients, the results of the study showed that 6MWT and the decrease of gait velocity were good predictors of ability to walk uphill. On the contrary, no such predictor was found for ramp descent.

\section{ACKNOWLEDGMENTS}

\section{Author Contributions:}

Study concept and design: X. Bonnet, F. Lavaste, N. Martinet, P. Fodé, H. Pillet.

Acquisition of data: K. Langlois, C. Villa, P. Fodé, N. Martinet, H. Pillet. Analysis and interpretation of data: K. Langlois, C. Villa, X. Bonnet, H. Pillet.

Drafting of manuscript: K. Langlois, C. Villa, H. Pillet.

Critical revision of manuscript for important intellectual content:

K. Langlois, C. Villa, X. Bonnet, F. Lavaste, N. Martinet, P. Fodé, H. Pillet.

Study supervision: F. Lavaste, N. Martinet, P. Fodé, H. Pillet.

Obtained funding: X. Bonnet, F. Lavaste, N. Martinet, P. Fodé, H. Pillet. Financial Contributions: The authors have declared that no competing interests exist.

Funding/Support: This material was based on work supported by the French National Research Agency (grant ANR-2010-TECS-020).

Institutional Review: The protocol was approved by the local ethics committee and all participants gave their consent.

Participant Follow-Up: The authors plan to inform participants of the publication of this study.

\section{REFERENCES}

1. Maffiuletti NA. Assessment of hip and knee muscle function in orthopaedic practice and research. J Bone Joint Surg Am. 2010;92(1):220-29. [PMID:20048117] http://dx.doi.org/10.2106/JBJS.I.00305

2. Raya MA, Gailey RS, Fiebert IM, Roach KE. Impairment variables predicting activity limitation in individuals with lower limb amputation. Prosthet Orthot Int. 2010;34(1):73-84. [PMID:20196689] http://dx.doi.org/10.3109/03093640903585008

3. Sagawa Y Jr, Turcot K, Armand S, Thevenon A, Vuillerme $\mathrm{N}$, Watelain E. Biomechanics and physiological parameters during gait in lower-limb amputees: A systematic review. Gait Posture. 2011;33(4):511-26. [PMID:21392998] http://dx.doi.org/10.1016/j.gaitpost.2011.02.003

4. Vanicek N, Strike SC, McNaughton L, Polman R. Lower limb kinematic and kinetic differences between transtibial amputee fallers and non-fallers. Prosthet Orthot Int. 2010; 34(4):399-410. [PMID:20450461] http://dx.doi.org/10.3109/03093646.2010.480964 
5. Lloyd CH, Stanhope SJ, Davis IS, Royer TD. Strength asymmetry and osteoarthritis risk factors in unilateral transtibial, amputee gait. Gait Posture. 2010;32(3):296-300. [PMID:20678938] http://dx.doi.org/10.1016/j.gaitpost.2010.05.003

6. Lay AN, Hass CJ, Gregor RJ. The effects of sloped surfaces on locomotion: A kinematic and kinetic analysis. J Biomech. 2006;39(9):1621-28. [PMID:15990102] http://dx.doi.org/10.1016/j.jbiomech.2005.05.005

7. Hansen AH, Childress DS, Miff SC. Roll-over characteristics of human walking on inclined surfaces. Hum Mov Sci. 2004;23(6):807-21. [PMID:15664674] http://dx.doi.org/10.1016/j.humov.2004.08.023

8. McIntosh AS, Beatty KT, Dwan LN, Vickers DR. Gait dynamics on an inclined walkway. J Biomech. 2006; 39(13):2491-2502. [PMID:16169000] http://dx.doi.org/10.1016/j.jbiomech.2005.07.025

9. Sadeghi H, Allard P, Duhaime PM. Muscle power compensatory mechanisms in below-knee amputee gait. Am J Phys Med Rehabil. 2001;80(1):25-32. [PMID:11138951] http://dx.doi.org/10.1097/00002060-200101000-00007

10. Devita P, Janshen L, Rider P, Solnik S, Hortobágyi T. Muscle work is biased toward energy generation over dissipation in non-level running. J Biomech. 2008;41(16):3354-59. [PMID:19010471] http://dx.doi.org/10.1016/j.jbiomech.2008.09.024

11. Vrieling AH, van Keeken HG, Schoppen T, Otten E, Halbertsma JP, Hof AL, Postema K. Uphill and downhill walking in unilateral lower limb amputees. Gait Posture. 2008;28(2): 235-42. [PMID:18242995] http://dx.doi.org/10.1016/j.gaitpost.2007.12.006

12. Vickers DR, Palk C, McIntosh AS, Beatty KT. Elderly unilateral transtibial amputee gait on an inclined walkway: A biomechanical analysis. Gait Posture. 2008;27(3):518-29. [PMID:17707643] http://dx.doi.org/10.1016/j.gaitpost.2007.06.008

13. Fradet L, Alimusaj M, Braatz F, Wolf SI. Biomechanical analysis of ramp ambulation of transtibial amputees with an adaptive ankle foot system. Gait Posture. 2010;32(2): 191-98. [PMID:20457526] http://dx.doi.org/10.1016/j.gaitpost.2010.04.011

14. Powers CM, Boyd LA, Fontaine CA, Perry J. The influence of lower-extremity muscle force on gait characteristics in individuals with below-knee amputations secondary to vascular disease. Phys Ther. 1996;76(4):369-77, discussion 378-85. [PMID:8606900]

15. Pillet H, Bonnet X, Lavaste F, Skalli W. Evaluation of force plate-less estimation of the trajectory of the centre of pressure during gait. Comparison of two anthropometric models.
Gait Posture. 2010;31(2):147-52. [PMID:19864138]

http://dx.doi.org/10.1016/j.gaitpost.2009.09.014

16. Loiret I, Paysant J, Martinet N, André JM. [Evaluation of amputees]. Ann Readapt Med Phys. 2005;48(6):307-16.

French. [PMID:15932782]

http://dx.doi.org/10.1016/j.annrmp.2005.03.009

17. Miller WC, Deathe AB, Speechley M. Lower extremity prosthetic mobility: A comparison of 3 self-report scales. Arch Phys Med Rehabil. 2001;82(10):1432-40.

[PMID:11588750] http://dx.doi.org/10.1053/apmr.2001.25987

18. Neptune RR, Kautz SA, Zajac FE. Contributions of the individual ankle plantar flexors to support, forward progression and swing initiation during walking. J Biomech. 2001;34(11):1387-98. [PMID:11672713]

19. Neptune RR, Zajac FE, Kautz SA. Muscle force redistributes segmental power for body progression during walking. Gait Posture. 2004;19(2):194-205. [PMID:15013508]

20. Fraisse N, Martinet N, Kpadonou TJ, Paysant J, Blum A, André JM. [Muscles of the below-knee amputees]. Ann Readapt Med Phys. 2008;51(3):218-27. French. [PMID:18358554]

http://dx.doi.org/10.1016/j.annrmp.2008.01.012

21. Hunter LC, Hendrix EC, Dean JC. The cost of walking downhill: Is the preferred gait energetically optimal? J Biomech. 2010;43(10):1910-15. [PMID:20399434] http://dx.doi.org/10.1016/j.jbiomech.2010.03.030

22. Schmalz T, Blumentritt S, Jarasch R. Energy expenditure and biomechanical characteristics of lower limb amputee gait: The influence of prosthetic alignment and different prosthetic components. Gait Posture. 2002;16(3):255-63. [PMID:12443950]

Submitted for publication June 5, 2013. Accepted in revised form August 20, 2013.

This article and any supplementary material should be cited as follows:

Langlois K, Villa C, Bonnet X, Lavaste F, Fodé P, Martinet $\mathrm{N}$, Pillet H. Influence of physical capacities of males with transtibial amputation on gait adjustments on sloped surfaces. J Rehabil Res Dev. 2014;51(2):193-200. http://dx.doi.org/10.1682/JRRD.2013.05.0118

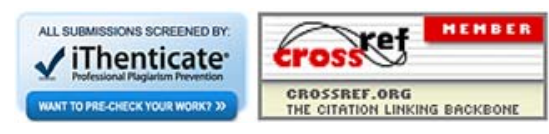

